\title{
FORMAÇÃO CONTINUADA DE PROFESSORES: O CIRCO EM DEBATE
}

\author{
CONTINUING TEACHER EDUCATION: THE CIRCUS IN \\ DEBATE
}

\section{FORMACIÓN CONTINUADA DE PROFESORES: EL CIRCO EN DEBATE}

\author{
Michelle Guidi Gargantini Presta ${ }^{1}$ \\ https://orcid.org/0000-0002-6675-9461 \\ Rita de Cássia Fernandes Miranda ${ }^{2}$ \\ https://orcid.org/0000-0001-8935-8786 \\ Mônica Caldas Ehrenberg ${ }^{3}$ \\ https://orcid.org/0000-0002-2445-1362
}

\footnotetext{
${ }^{1}$ Universidade Estadual de Campinas, Campinas, São Paulo - Brasil. E-mail: mipresta@ hotmail.com. 2 Universidade Federal de Uberlândia, Uberlândia, Minas Gerais - Brasil. E-mail: rita.miranda@ufu.br.

${ }^{3}$ Universidade de São Paulo, São Paulo, São Paulo - Brasil. E-mail: monica.ce@usp.br.
}

\section{Resumo}

O universo circense tornou-se objeto de estudo e foi elemento disparador de inúmeras possibilidades na Educação Infantil. A partir de uma metodologia qualitativa de cunho exploratório, objetivou-se analisar as contribuições, os desafios e as possibilidades de desenvolver um projeto circense no âmbito da Educação Infantil em uma unidade escolar situada no interior de São Paulo. Foi possível identificar professoras em processo de formação, crianças em plenas descobertas, equipe gestora e familiares partícipes da construção dos conhecimentos circenses. Entre os resultados, destaca-se a reflexão sobre diferentes aspectos da dinâmica escolar, além das tomadas de decisão coletivas que fortaleceram os vínculos e transformaram o espaço construído e compartilhado.

Palavras-chave: Educação Infantil. Formação Continuada. Circo.

\section{Abstract}

The circus universe becomes object of study being trigger element of numerous possibilities on early childhood education. From a qualitative methodology of exploratory nature, aimed to analyze the contributions, challenges and possibilities for developing a circus project in the 
field of early childhood education in a school unit located in the interior of São Paulo. It was possible to identify teachers in training process, children in full findings, management team and family participants of the construction of circus skills. Among the results was the reflection on different aspects of school dinamics, in addition to the collective decision making that have strengthened the links and transformed the space built and shared.

Keywords: Early Childhood Education. Continuing Education. Circus.

\section{Resumen}

El universo circense se ha vuelto en objeto de estudio, siendo elemento disparador de innúmeras posibilidades en la Educación Infantil. Desde de una metodología cualitativa de cuño exploratorio, se trataron de analizar las contribuciones, los desafíos y posibilidades del desarrollo de un proyecto circense en el ámbito de la Educación Infantil en una unidad escolar ubicada en el interior de São Paulo. Ha sido posible identificarse profesoras en constante proceso de formación, niños(as) en plenos descubrimientos, equipo gestor $y$ familiares partícipes de la construcción de los conocimientos circenses. Entre los resultados se destaca la reflexión sobre distintos aspectos de la dinámica escolar, además de las tomadas de decisión colectivas que fortalecieron los vínculos y transformaron el espacio construido y compartido.

Palabras clave: Educación Infantil. Formación Continuada. Circo.

\section{Introdução: pelos bastidores do espetáculo}

A compreensão da formação continuada de professores como possibilidade de desenvolvimento profissional, produção de conhecimentos e socialização requer olhares mais críticos de todos os envolvidos no processo educacional. Na mesma direção, pensar os modos como o circo tem sido abordado nesse contexto exige um cuidado ampliado a fim de identificarmos as diferentes concepções veiculadas sobre o próprio circo e os sujeitos que nele operam na condição de fenômeno constituinte da cultura do corpo e linguagem artística.

É notório que o circo vem cada vez mais chamando a atenção de educadores de diferentes áreas do conhecimento e ocupando múltiplos espaços educativos. Matizado em sua potência de se reinventar (BORTOLETO; SILVA, 2017), o circo nos brinda com um cenário

que de algum modo desperta a educação formal ou institucionalizada para este diálogo. Assim, vemos interessantes projetos de diferentes naturezas sendo desenvolvidos desde a educação básica até o ensino superior em diversas regiões brasileiras, inclusive com disciplinas específicas que tratam do circo na formação de professores (MIRANDA; AYOUB, 2017; MIRANDA; BORTOLETO, 2014). 
Nessa perspectiva, e considerando a experiência vivenciada na unidade escolar Terê ${ }^{1}$, localizada em um munícipio do interior de São Paulo, optamos por realizar um estudo exploratório, tendo como objetivos analisar as contribuições, os desafios e as possibilidades do desenvolvimento de um projeto circense no âmbito da Educação Infantil.

Diante dos objetivos propostos, analisaremos a seguir as experiências vividas com o ensino do circo na escola pesquisada, especificamente no trabalho realizado com a equipe de professoras durante suas formações.

\section{Compondo a cena: a formação continuada de professoras}

Para que uma cena ou um espetáculo inteiro sejam desenvolvidos e se completem no encontro com o público, é necessário trabalho árduo de diferentes atores sociais, principalmente nos bastidores. Nem sempre o investimento focado em seu próprio personagem supre as necessidades de um espetáculo como um todo, sendo desejável que o coletivo sobressaia.

É preciso traçar o enredo (objetivos), reconhecer todos os atores da cena (alunos, professores, pais e gestores), ensaiar tecnicamente e artisticamente a cena (reconhecer processos pedagógicos), encontrar maneiras favoráveis para cada atuação (metodologias de ensino), preparar (aulas) e, enfim, apresentar-se (avaliar). Todo esse caminho se assemelha ao processo de ensino e aprendizado nas escolas. Não basta ministrar a aula em si, pois ela é apenas uma parte do episódio.

Inúmeros conhecimentos necessários ao exercício da docência são (re)construídos num processo de formação que não se esgota. É aprendizagem que se transforma e se ressignifica durante toda a carreira docente. Autores como Tardif (2002) e Pimenta (2002) definem tais conhecimentos como saberes que fundamentam uma ampla gama de habilidades e competências que o docente desenvolve e mobiliza em sua prática pedagógica, seja ao longo de sua formação inicial ou continuada.

Por outro lado, não é novidade apontarmos que o debate contemporâneo sobre a formação continuada de professores como elemento fundamental para a prática docente se

\footnotetext{
${ }^{1}$ Trata-se de uma denominação dada pela própria comunidade local para a escola. Optamos por utilizá-la, visando a tanto manter guardada a identidade oficial da unidade escolar quanto valorizar as vozes dos participantes da pesquisa.
} 
PRESTA, M. G. G.; MIRANDA, R. de C. F.; EHRENBERG, M. C.

intensificou nos últimos anos, em especial após a promulgação da Lei de Diretrizes e Bases da Educação Nacional (LDBEN) - Lei no 9.394/1996 (BRASIL, 1996), do Plano Nacional de Educação 2014-2024 (PNE) - Lei n 13.005/2014 (BRASIL, 2014), bem como das diretrizes curriculares nacionais para a formação de professores da educação básica (BRASIL, 2015).

Quando nos debruçamos sobre os aspectos históricos da educação, constatamos que a ideia de formação continuada já fazia parte dos projetos educativos desde a Paideia grega. Segundo Lippi (2009), no Brasil em particular, desde os anos de 1990, na tentativa de superar os graves problemas de acesso e assegurar a permanência dos alunos em escolas públicas, muitas mudanças têm ocorrido na educação brasileira: reformas curriculares, avaliações sistemáticas em níveis nacional e estadual, implementação do sistema de ciclos, entre outras. Essas tentativas de redemocratizar a educação pública causaram, no entanto, desequilíbrios entre a ampliação da oferta de vagas e as possibilidades das escolas de atender bem aos seus alunos. Com isso, houve a precarização das condições de trabalho docente, e, no final da década de 1990, reconhecia-se que os professores brasileiros vinham recebendo uma formação insuficiente para promover a aprendizagem de seus alunos. É nesse contexto de dupla preocupação - com a qualidade da escolarização das crianças e com o desenvolvimento profissional e pessoal dos docentes - que a formação continuada de professores se torna alvo de interesse nesta pesquisa.

Indiscutivelmente, para se pensar em formação continuada, faz-se necessário refletir também sobre a profissão docente, a fim de compreender melhor o cenário e os atores desse processo. A esse respeito, Camilo Cunha (2015) pontua que a construção da profissão é um contínuo caminho que pressupõe fatores internos e externos manifestados pelas variáveis éticas e deontológicas, pela identidade profissional, pela construção de programas, pelos componentes práticos e teóricos da formação, pela formulação em nível organizacional, curricular e institucional, pelas filosofias formativas, pelas questões epistemológicas, entre tantos outros fatores.

De acordo com Neira (2008), os cursos de graduação geralmente ensinam a seus concluintes a necessidade de manter uma eterna postura de alunos. $\mathrm{O}$ autor ainda contribui com a reflexão, afirmando que comumente os professores estão despreparados para exercer a função docente diante de novos contornos sociais, que trazem para as escolas alunos provenientes de repertório cultural amplo, caracterizando uma heterogeneidade escolar. 
Por outro lado, numa análise macro, encontramo-nos num novo contexto - global, técnico, complexo, multicultural -, em que o conhecimento profissional (e pessoal) não poderá esquecer esses novos cenários. Sendo assim, conferimos aqui dois motivos legítimos para a continuidade do aperfeiçoamento profissional.

A multiplicidade de funções atribuídas aos professores exige um elevado nível de profissionalismo que não se circunscreve apenas aos domínios e às técnicas referentes aos componentes curriculares, pois esse paradigma pautado numa racionalidade técnica, que afirma bastar que o professor seja um transmissor de conhecimentos, não corresponde mais ao que se espera da prática docente no século XXI.

Além da formação acadêmica e pedagógica, torna-se fundamental também uma formação prática, cultural e investigativa. Tal formação pode se dar tanto no âmbito acadêmico, com os estágios e a prática como componente curricular, quanto pode, principalmente, ser aperfeiçoada durante a formação continuada.

Camilo Cunha (2015) afirma que a formação ao longo da vida é um aspecto fundamental para interagir com as mudanças sociais, econômicas, tecnológicas e, consequentemente, com as novas concepções educacionais. Ademais, o professor inserido na nova configuração social torna-se limitado se fornecer explicações sob uma única lógica, por isso é preciso uma formação que contemple análises de produções culturais sob diferentes pontos de vista.

Nossa intenção disparadora para o processo desta pesquisa foi justamente possibilitar que as professoras sentissem "na pele" o que poderiam as práticas corporais (circenses, neste caso) oferecer, sendo mais do que mero passatempo ou extravasamento de energia. Ensejávamos que as professoras, ao sentirem as potencialidades das práticas corporais, pudessem clamar por trabalhos continuados acerca dessa formação. Não mais porque algum gestor determinou, mas porque elas, as próprias professoras, estivessem tocadas pela necessidade de apropriar-se efetivamente desses conhecimentos.

Esse foi o caminho planejado para o projeto aqui proposto: a partir do despertar das próprias professoras para o interesse acerca das práticas corporais circenses, fomentar, posteriormente, reverberações dessas ações pela condução das professoras em suas aulas e pelo aclamar de políticas formativas acerca dessa temática. 


\section{No centro do picadeiro: o circo na formação continuada de professores}

O crescimento da produção acadêmica e a efervescência da temática da formação continuada parecem aplicar-se também às discussões sobre o circo, seja nas escolas básicas, nos projetos sociais, nas escolas profissionalizantes de circo, nas universidades ou nos contextos de formação de professores, como sugerem estudos anteriores (MIRANDA, 2015; MIRANDA, AYOUB, 2017; MIRANDA, BORTOLETO, 2018).

Por meio das pesquisas citadas, analisamos diferentes processos de implementação e os desdobramentos da presença do circo como componente curricular na formação inicial em Educação Física em duas Instituições de Ensino Superior do estado de São Paulo. Os resultados apontaram a participação efetiva dos docentes e discentes nas ações extensionistas, de ensino e de pesquisa, propiciando visibilidade à temática circense ao contribuir para a legitimação desses conhecimentos no currículo. Além disso, identificamos diferentes desdobramentos, como a consolidação de grupos de estudos e pesquisas, a organização de eventos, a profissionalização artística de muitos ex-alunos(as) dessas instituições, um conjunto significativo de publicações, além de diferentes possibilidades de formação continuada, porém os dois casos analisados não se configuram maioria na realidade brasileira. $^{2}$

Como vimos, o circo sinaliza em que medida sua presença na formação continuada de professores pode contribuir para a consecução de um projeto mais amplo de educação corporal, artística e estética (BORTOLETO, 2011). Por certo, almejamos que o circo e os sujeitos que operam essa linguagem possam subverter concepções cristalizadas e universalizantes sobre as práticas corporais, ressaltando suas múltiplas formas de expressão, de articulação com outras esferas da sociedade e, também, seu encontro com outras linguagens artísticas. Apesar de asseverarmos que "as gretas da universidade parecem ser mais estreitas, dificultando o surgimento das iniciativas circenses" (BORTOLETO; SILVA, 2017), constatamos a capacidade do circo de ser o rizoma que, a cada encontro de alteridades, modifica-se em sua secular trajetória.

\footnotetext{
${ }^{2}$ Esses achados são corroborados por outra pesquisa, por meio da qual investigamos os currículos dos cursos superiores de Pedagogia de universidades públicas paulistas. O contexto encontrado, todavia, sugere ainda pouca atenção dada ao circo como fenômeno da cultura corporal (MIRANDA; BORTOLETO, 2014).
} 
Respaldadas nessas ponderações, defendemos a pertinência de repensar os atuais modelos formativos e as políticas de formação continuada de professores, ainda mais quando entendemos que o seu papel seria apenas suprir as lacunas da formação inicial, propiciando a capacitação profissional docente.

Cabe sublinhar que a formação continuada de professores constituída unicamente por eventos esporádicos, desvinculados das especificidades dos diferentes contextos escolares, bem como das necessidades de desenvolvimento profissional dos professores, não tem contribuído para mudanças reais na prática pedagógica e tampouco no cenário educativo de forma geral. Muitos programas ainda ocorrem de maneira compulsória, com conteúdo determinado por esferas superiores e pautados em interesses exclusivamente institucionais (REIS; AFONSO, 2007; SILVA, 2000). Além disso, não podemos desconsiderar os inúmeros problemas estruturais da sociedade e do cenário educacional brasileiro que, certamente, condicionam a formação continuada.

Por outro lado, relatos de experiência publicados recentemente (BORTOLETO, 2011; ONTAÑ́́N; DUPRAT; BORTOLETO; 2012; MIRANDA; AYOUB, 2017) revelam que muitos docentes, em grande parte motivados por diferentes processos de formação continuada, vêm desenvolvendo experiências pedagógicas e propostas interdisciplinares com o circo na Educação Infantil (CORSI; DE MARCO; ONTAÑÓN, 2018) e nos Ensinos Fundamental e Médio (ONTAÑ́́N, 2016), entretanto muitos ainda têm atuado de forma autodidata e intuitiva, orientados por aspirações pessoais.

Ora, não é raro nos deparamos com os escassos argumentos apresentados por docentes que não dão conta de justificar o tratamento e as decisões pedagógicas tomadas nos processos de ensino e aprendizagem do circo. Evidentemente, não queremos que tal realidade nos comprometa num futuro próximo, mas pretendemos aprofundar o entendimento dos códigos que compõem a linguagem circense banhada em sua historicidade. Claro está que a ausência de processos colaborativos de formação continuada em busca da resolução dos problemas oriundos do contexto profissional tem levado muitos docentes, na ânsia por renovar suas aulas com "novos conhecimentos", a acessar os conhecimentos circenses, não mais na condição de espectadores, mas como protagonistas do processo.

A recente pesquisa de Chioda (2018) ilustra a problemática em tela, pois o autor, como professor de Educação Física, percebendo a necessidade de renovar suas práticas pedagógicas, vê no circo o potencial lúdico e educativo, pautado na relevância sócio-histórico-cultural 
desse fenômeno. Suas experiências docentes possibilitaram o compartilhamento com outros colegas de profissão por meio do oferecimento de uma proposta de formação continuada voltada para os professores da rede pública de uma cidade do interior de São Paulo que também ansiavam por tematizar o circo em suas aulas.

Outros trabalhos que discutem possibilidades pedagógicas com o circo na formação continuada de professores e na extensão universitária (ABRAHÃO, 2011; TIAEN, 2013) sinalizam a transversalidade desses conhecimentos, além da receptividade dos sujeitos envolvidos com os saberes circenses. Essas pesquisas analisam os desafios encontrados e a carência de propostas pedagógicas que valorizem o circo como linguagem artística, em que o sensível e o gesto sejam elementos centrais.

Por outro lado, podemos inferir que a "invisibilização" desses conhecimentos na formação de professores está sendo revista por meio de outras perspectivas que dialogam com os componentes artísticos e expressivos da cultura corporal. Ademais, notamos que boa parte da produção acadêmica decorre de contextos nos quais o circo foi abordado na formação inicial desses professores, provavelmente fomentando distintas experiências pedagógicas e "[...] um olhar atento à diversidade artística, que inclua o circo" (BORTOLETO; SILVA, 2017, p. 114).

Para Silva (2016), são esses "novos sujeitos históricos" que interagem na produção da linguagem circense, ou seja, são docentes, pesquisadores de diferentes áreas de conhecimento, autodidatas, artistas, alunos que nunca deixaram de ser sinérgicos ao seu tempo. Com isso, é possível ratificarmos a polissemia e a pluralidade do circo, que paulatinamente ganha espaço nos cursos de formação profissional e na formação continuada de professores.

Foi nesse cenário idealizado coletivamente de professoras da unidade escolar "Terê" que as práticas corporais circenses passaram a integrar a formação continuada da equipe.

\section{Primeiro ato: em foco o planejamento do trabalho coletivo}

A escolha do trabalho pedagógico por meio de projetos tem sido uma prática recorrente nessa unidade escolar. A temática do circo foi lançada como sugestão pela coordenação, na última reunião do ano de 2016, como possibilidade de trabalho coletivo, de pesquisa e de formação continuada, com a proposta de compreender o circo em suas diferentes perspectivas de apropriação crítica, tendo sido acolhida por toda a comunidade 
escolar. Naquele momento, tínhamos a convicção de que “[...] o trabalho em equipe e os projetos de formação podem ser elementos que favoreçam o comprometimento de todos com o projeto da escola" (DOMINGUES, 2014, p. 78).

No início de 2017, na reunião de planejamento, tivemos a oportunidade de retomar a ideia e traçar algumas ações. O projeto teria a duração anual, algo novo para a equipe, pois sempre tivemos o hábito de fazer projetos semestrais.

De maneira geral, definimos os seguintes objetivos do Projeto Circo: reconhecer e respeitar a diversidade cultural; resgatar o conhecimento e as memórias das famílias sobre o circo; ampliar o repertório sobre a temática do circo; vivenciar práticas circenses (professores e alunos) nos âmbitos das práticas corporais e das expressões artísticas; e incentivar a busca pelo conhecimento por meio de pesquisas.

Reunindo as estratégias de ação e as formas de documentação, faríamos um livro de registros elaborado pelos alunos com os seus familiares. Assim, cada turma escolheu um personagem circense para identificá-la e também um brinquedo que representasse o circo para proporcionar momentos de brincadeira e interação familiar ${ }^{3}$, como mostra o Quadro 1.

Quadro 1 - Personagens, turmas e brinquedos/acessórios escolhidos pelas turmas.

\begin{tabular}{|l|l|l|}
\hline Personagem & Turma & Acessórios na sacola \\
\hline Palhaço & Berçário & Boneco de pano; nariz; peruca \\
\hline Trapezista & Maternal II & Boneco de madeira que gira \\
\hline Mágico & Maternal III & Cartola; capa; varinha \\
\hline Equilibrista & Maternal I & Pé de lata \\
\hline Malabarista & Maternal II & Clave com garrafa pet; bolas de bexiga \\
\hline Contorcionista & Maternal I & $\begin{array}{l}\text { Boneco de pano com velcro nas mãos e } \\
\text { nos pés }\end{array}$ \\
\hline
\end{tabular}

Fonte: Elaborado pelas autoras.

\footnotetext{
${ }^{3}$ Cada sacola foi montada com o acessório, um caderno de desenho para registro posterior às brincadeiras, lápis, caneta, borracha, lápis de cor, giz de cera e caneta hidrocor. Depois do vivido, cada família poderia representá-lo da maneira que fosse mais confortável, com escrita, desenho, fotos etc.
} 
Combinamos que cada turma iria confeccionar um móbile relacionado com a temática circense e o personagem da turma para enfeitar a escola. O prédio ficou colorido e repleto de elementos que nos remetiam à temática do projeto.

Figura 1 - Materiais (móbiles) e participantes do projeto
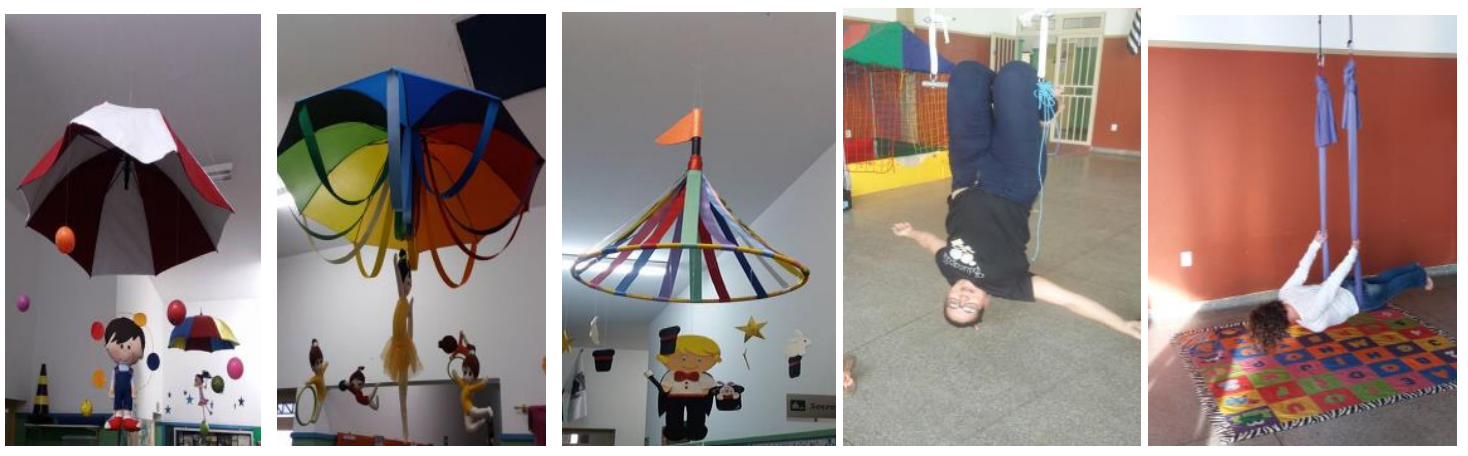

Fonte: Acervo das pesquisadoras.

$\mathrm{Na}$ unidade escolar, valorizam-se ações que envolvam a família, propiciando interação, a fim de mostrar aos pais e/ou responsáveis o que é desenvolvido não somente na rotina diária. Ratificamos a relevância da participação das famílias na vida escolar, sobretudo nos anos iniciais da escolarização, algo que é destacado como estratégia fundamental ao processo de ensino-aprendizado em diferentes documentos oficiais, publicações e declarações internacionais, entre elas a Declaração Mundial sobre Educação para Todos (UNESCO, 1990), corroborada pela Conferência de Dacar em 2000.

Como parte da formação docente, propusemos um intercâmbio das turmas, pois, em diversos momentos, as professoras precisaram trabalhar coletivamente, dialogar, compor materiais e executar as tarefas acordadas pelo grupo. Conforme apontado no Quadro 1, cada grupo de personagem foi composto por uma turma da creche e uma da pré-escola, e isso possibilitou uma comunicação mais efetiva entre as professoras. "É no coletivo da escola que surgem os desafios, que se definem os caminhos a ser percorridos, em que a ação e a formação se complementam" (CAMPOS, 2014, p. 53).

O processo vivido nos fez identificar as várias dimensões do trabalho coletivo na escola, pois entendemos esse último como mecanismo fundamental para a melhoria da qualidade de ensino; entretanto, como afirma Chaluh (2010, p. 221), "fazer um trabalho 
coletivo não implica apagar as diferenças entre os sujeitos envolvidos". Abraçamos esse desafio de aprender com o outro a partir das diferenças, tendo clareza de que esse caminhar junto não refletiu necessariamente, a todo momento, que as decisões tomadas no grupo fossem consensuais.

\section{Segundo ato: cenas da implementação do projeto na escola}

Partindo dos objetivos elencados, ficou acordado com a equipe pedagógica que parte do horário da formação em serviço seria destinada também para a elaboração de materiais pedagógicos, espaço de vivências, discussões e pesquisas sobre a temática do circo. Desse modo, durante os encontros foram discutidos textos alusivos à temática circense em consonância com as práticas pedagógicas escolares e a formação de professores. A partir das leituras e das reflexões surgiram algumas propostas, uma delas foi convidar profissionais com experiência na área circense que ministrassem oficinas para que as professoras pudessem vivenciar diferentes modalidades, como as acrobacias, os malabares e os aéreos.

Naquele momento, a equipe de professoras reconhecia que possuía um conhecimento reduzido e poucas vivências das inúmeras modalidades circenses. Mesmo já tendo experimentado a condição de espectadoras, tal fato dificultava as vivências com as práticas circenses e exigia, portanto, maior pesquisa e dedicação pautada "por um paradigma apoiado no trabalho coletivo, na investigação, pelos professores, da prática pedagógica e na cooperação dos educadores em prol do desenvolvimento profissional e da melhoria da educação" (DOMINGUES, 2014, p. 72).

Logo no início do mês de março de 2017, fizemos uma formação com o tema "Meu mundo de cabeça para baixo" com as professoras da creche e da pré-escola no HAPE ${ }^{4}$. Algumas professoras concordaram em experimentar rolamentos, parada de mãos e tantas outras atividades corporais "desafiadoras" e compartilhar memórias das brincadeiras de infância. Enfatizamos que aqueles eram conhecimentos que poderiam fazer parte das aulas e que, com responsabilidade e estratégias adequadas, poderiam ser muito seguros para as crianças. Destacamos que houve grande preocupação quanto à gestão do risco e à construção

\footnotetext{
${ }^{4}$ A partir do mês de agosto de 2012, foi instituído o horário de trabalho pedagógico na escola (HAPE) no município pesquisado.
} 
de uma "cultura de segurança" nas aulas, levando-nos a organizar previamente o espaço das vivências e checar as condições dos materiais (FERREIRA; BORTOLETO; SILVA, 2014).

Apesar disso, importa ressaltar a questão do risco estético e simbólico do circo como elemento fundante e atrativo desse universo (GUZZO, 2009; WALLON, 2000). Talvez essa questão do risco, do medo, do virtuosismo enaltecido nas práticas circenses tenha sido um dos fatores desafiadores tanto para as professoras participantes do projeto, quanto para nós, que conduzíamos o processo.

Durante as formações as professoras se posicionavam como não capazes em realizar as atividades propostas, justificando sentirem dores nas articulações, por considerarem que a idade poderia dificultar ou, ainda, em grande proporção, o medo era trazido como impeditivo. Isso aconteceu muito nas vivências de solo com as atividades de rolamento, parada de mãos, ginástica acrobática, mas também nos aéreos de trapézio e tecido. Poucas professoras participaram efetivamente desse processo; a maioria participou como ouvinte e/ou como auxiliar das professoras que estavam fazendo os exercícios.

Em alguns momentos, as professoras disseram ter receio de que as crianças se machucassem, podendo o enfrentamento com os pais ser mais um desafio. Essa discussão apareceu em muitos momentos. Conversamos sobre um planejamento bem estruturado e consolidado desses conteúdos e a necessidade de as professoras estarem seguras do que seria proposto aos alunos. Dessa maneira, quaisquer problemas teriam condições de justificar a natureza de um possível machucado, por exemplo. Reconhecemos que mesmo as professoras que não experimentaram o rolamento na prática se sentiram estimuladas e confiantes para realizar com as crianças.

“Tinha medo de dar cambalhota, mas, depois que aprendi a ensinar e segurar as crianças, me senti mais segura pra trabalhar com eles" (professora Regina ${ }^{5}$ durante nossos encontros).

Na mesma direção, a professora Celia reconhece a importância dos encontros práticos em que pudemos vivenciar e experimentar as atividades antes de propô-las para as crianças:

"As vivências foram fundamentais no processo, experimentar antes de propor às crianças nos ajuda a entender os medos e as dificuldades" (professora Celia durante nossos encontros). 
Num segundo momento, foi proposta uma pesquisa sobre brincadeiras e exercícios de flexibilidade e equilíbrio. O circuito com bancos, cordas, muretas e fitas no chão foi o mais utilizado para proporcionar as vivências com os alunos. Além da criação de novos espaços e materiais para tais atividades, é necessário observar o que a escola já tem para desenvolver as vivências relacionadas com o tema. As poses acrobáticas foram igualmente exploradas e uma novidade tanto para os alunos quanto para as professoras.

Figura 2 - Professoras e crianças participantes do projeto.
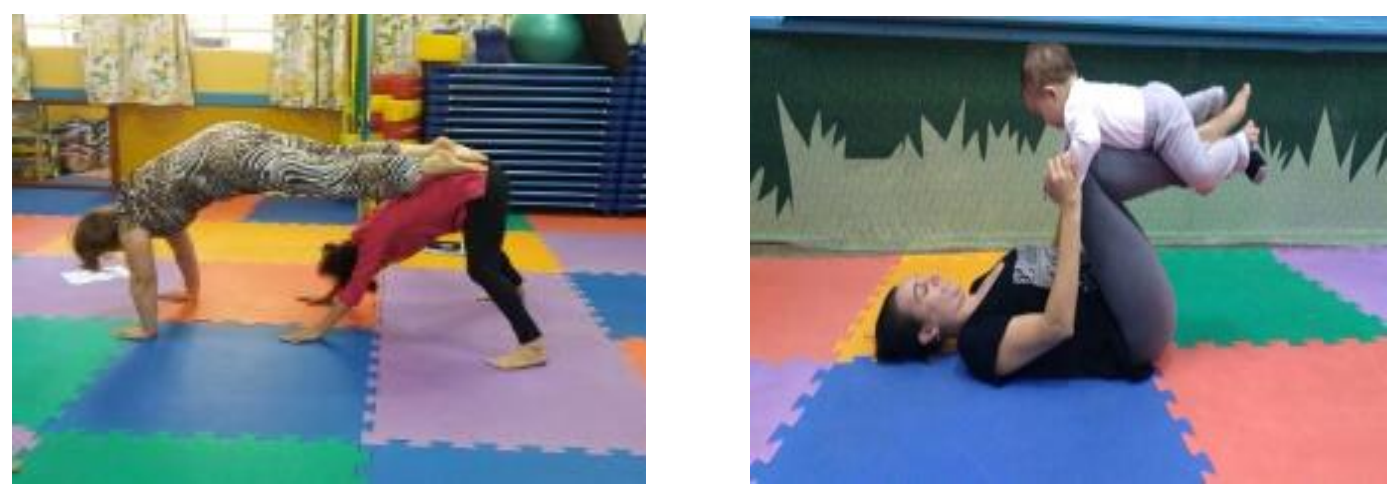

Fonte: Acervo das pesquisadoras.

Por certo, entendemos que o circo pode estar presente na escola de diversas maneiras, seja nas artes corporais, nas artes plásticas, na literatura, nas brincadeiras, nos vídeos, possibilitando a implementação da temática. Assim, "elaborar uma pedagogia das atividades circenses requer pensar em cores" (ONTAÑ́n, 2016, p. 144), formas, espaços e estratégias múltiplas.

Sabemos que o circo traz em seu histórico a inversão, a subversão e o prazer. Ademais, acreditamos na viabilidade de essas características contribuírem para que alguns conhecimentos cheguem à Educação Infantil, de maneira a valorizar o ser criança para "vivenciar, explorar e entender as manifestações artístico-corporais, seu próprio corpo, suas possibilidades e seu potencial comunicador" (CORSI; DE MARCO; ONTAÑÓN, 2018).

Na mesma direção, Ehrenberg (2015) ressalta a necessidade de reconhecimento da cultura corporal como sistematizadora da linguagem do corpo e, essa, como fonte de produção do gesto e da expressão na Educação Infantil. Defendemos que o circo, por suas características peculiares e receptivas ao brincar, pode ser uma fonte privilegiada para que a 
PRESTA, M. G. G.; MIRANDA, R. de C. F.; EHRENBERG, M. C.

Educação Infantil valorize diferentes linguagens e tenha como ponto de partida as próprias crianças, tal qual já nos alertou Ayoub (2001). A partir desses entendimentos, foi possível acreditar que as manifestações circenses seriam promissoras e disparadoras de ricos conhecimentos para as crianças e para as professoras. Enxergamos a possibilidade de apropriação dos conhecimentos por meio da intencionalidade para o lúdico, o artístico e o estético, como relata a professora Cássia: “Os projetos que envolvem o corpo-movimento são mais significativos".

Aqui podemos destacar outro desafio da proposta, mas que consideramos ter sido superado. Ampliar o conceito de movimento, alargando-o para o entendimento de gesto. $\mathrm{O}$ material norteador do município em que atuávamos apresenta os conteúdos e objetivos para as diferentes faixas etárias de forma bem pontual, estanque, relacionados quase em exclusividade com o domínio e a execução de habilidades motoras. Nós, pesquisadoras, não reconhecíamos dessa forma e gostaríamos de propor essa ampliação do olhar da equipe participante. Trabalhar com a temática do circo nos ajudou e facilitou que as professoras pensassem nos conhecimentos propostos de maneira mais ampla, dentro de um contexto significativo, viabilizando a troca de experiências e as vivências de diferentes práticas corporais.

Ficamos muito satisfeitas com o reconhecimento da professora Maria ao mencionar que "Esse projeto ampliou as possibilidades de explorar o próprio corpo e perceber que ele faz parte de um todo, de um contexto bem maior que apenas motor".

A oficina de malabarismo trouxe ao grupo vivências significativas, pois favoreceu a experiência de algo que parecia complexo de realizar com as crianças. Para Lopes e Parma (2016), o baixo custo e a utilização de materiais alternativos são aspectos facilitadores dessa proposta, pois a construção do aparelho circense “[...] possibilita a aproximação de todos a uma das características que persistem até os dias de hoje: a criação e confecção de suas próprias ferramentas de trabalho" (LOPES; PARMA, 2016, p. xvi), sendo um relevante meio para o entendimento da riqueza do circo.

Identificamos também outros depoimentos das professoras sobre o quanto foi importante vivenciar antes de realizar com as crianças, "pensar sobre o movimento" por meio de diferentes estratégias. 


\begin{abstract}
Mas termino relatando através das diversas experiências novas que aprendi junto com as crianças e através desse projeto circo na escola, que veio despertar e trazer diversos tipos de habilidades ao nosso corpo, com um novo olhar [...], sabendo que temos de sempre praticar o que aprendemos para adquirirmos novos desafios e conhecimentos através de novas ideias. (Depoimento da professora Ana.)
\end{abstract}

Nem sempre o que pesquisamos e/ou vivenciamos é transferido para o planejamento, pois talvez necessite de adaptações e novas técnicas. Foi relevante reconhecer que cada pessoa traz sentidos e significados diferentes para as suas experiências e que, portanto, não se tratava apenas de transferir para as crianças o que era vivenciado pela equipe docente.

\title{
6 Gran finale: o fim e o começo de outras propostas
}

Na retomada dos objetivos desta pesquisa - analisar as contribuições, os desafios e as possibilidades do desenvolvimento de um projeto circense no âmbito da Educação Infantil -, entendemos que abordar essa temática na unidade escolar "Terê" possibilitou a construção de experiências desafiadoras e de novos conhecimentos no âmbito das práticas corporais tanto para a equipe pedagógica quanto para as crianças.

Passar pelos espaços formativos da equipe com as vivências corporais também modificou a ideia de reprodução. Ficou evidente que o que era feito com as professoras não necessariamente seria reproduzido com os alunos. Ressignificar conhecimentos foi primordial nesse processo, além de promover a reflexão das professoras acerca do que eram capazes de realizar e quais as possibilidades e as limitações de seus corpos. O medo de vivenciar algumas propostas, sentir-se desafiada e andar na "corda bamba" foram questões que refletimos com a equipe de professoras.

Ter o projeto realizado ao longo do ano nos deu a oportunidade de analisar muitos aspectos da dinâmica escolar e tomar as decisões coletivamente, algo que fortaleceu os vínculos e transformou o espaço partilhado. Além disso, ao considerarmos que a formação continuada na escola fomentou a pesquisa sobre a própria prática e favoreceu o "mergulho" no universo circense, tal processo impactou a comunidade escolar por meio do reconhecimento das potencialidades e da riqueza desse patrimônio cultural. 


\section{Referências}

ABRAHÃO, S. R. Valoración de las actividades circenses en la formación del profesorado de educación física: Una propuesta para la transformación social en la escuela. 2011. 485 f. Tese (Doutorado em 2011) - Facultad de Formación del Profesorado, Universidad de Barcelona, Barcelona, 2011. Disponível em: https://dialnet.unirioja.es/servlet/tesis?codigo=129692. Acesso em: 6 nov. 2018.

AYOUB, E. Reflexões sobre a Educação Física na Educação Infantil. Revista Paulista de Educação Física, São Paulo, (supl.4), p. 53-60, 2001. DOI: https://doi.org/10.11606/issn.2594-5904.rpef.2001.139594. Disponível em: https://www.revistas.usp.br/rpef/article/view/139594/134898. Acesso em: 19 mar. 2019.

BORTOLETO, M. A. C. Atividades circenses: notas sobre a pedagogia da educação corporal e estética. Cadernos de Formação RBCE, Brasília, v. 2, n. 2, p. 43-55, 2011. Disponível em: http://revista.cbce.org.br/index.php/cadernos/article/view/1256/651. Acesso em: 3 nov. 2018.

BORTOLETO, M. A. C.; SILVA, E. Circo: educando entre as gretas. Rascunhos, v. 4, n. 2, p. 104-117, 2017. DOI: https://doi.org/10.14393/issn2358-3703.v4n2a2017-07. Disponível em: http://www.seer.ufu.br/index.php/rascunhos/article/view/38646. Acesso em: 4 nov. 2018.

BRASIL. Lei no 9.394, de 20 de dezembro de 1996. Estabelece as Diretrizes e Bases da Educação Nacional. Diário Oficial da União, Brasília, 23 de dezembro de 1996.

BRASIL. Ministério da Educação. Fundamentos para formação do professor da educação básica. Brasília, 1999. Disponível em: http://portal.mec.gov.br/setec/arquivos/pdf/esbo\%E2\%80\%A1o4.pdf. Acesso em: 30 jun. 2018.

BRASIL. Lei $n^{\circ} 13.005$, de 25 de junho de 2014. Aprova o Plano Nacional de Educação PNE e dá outras providencias. Diário Oficial da União, Brasília, 26 jun. 2014.

BRASIL. Resolução CNE/CP n ${ }^{\circ}$ 02/2015, de $1^{\circ}$ de julho de 2015. Brasília, Diário Oficial [da] República Federativa do Brasil, seção 1, n. 124, p. 8-12, 2 jul. 2015.

CAMPOS, P. R. I. Ensinar e aprender: coordenação pedagógica e formação docente. Desenhos de Beatriz Infanger Campos. São Paulo: Loyola, 2014.

CHALUH, L. N. Do trabalho coletivo na escola: encontros na diferença. Pro-Posições, Campinas, v. 21, n. 2, p. 207-223, maio/ago. 2010. DOI: https://doi.org/10.1590/S010373072010000200013. Disponível em: https://www.scielo.br/scielo.php?pid=S0103$73072010000200013 \&$ script=sci_abstract\&tlng=pt. Acesso em: 30 jan. 2019.

CHIODA, R. Uma aventura da alegria e do risco: narrativas de um professor de educação física sobre o ensino das atividades circenses. 2018. 94 f. Tese (Doutorado em Educação Física) - Faculdade de Educação Física, Universidade Estadual de Campinas, Campinas-SP, 2018.

CORSI, L. M.; DE MARCO, A.; ONTAÑÓN, T. Educação Física na Educação Infantil: proposta interdisciplinar de atividades circenses. Pensar a Prática, Goiânia, v. 21, n. 4, 
out./dez. 2018. DOI: https://doi.org/10.5216/rpp.v21i4.51387. Disponível em: https://www.revistas.ufg.br/fef/article/view/51387. Acesso em: 19 mar. 2019.

CUNHA, A. C. Ser professor - bases de uma sistematização teórica. Chapecó-RS: Argos, 2015.

DOMINGUES, I. O coordenador pedagógico e a formação contínua do docente na escola. 1. ed. São Paulo: Cortez, 2014.

EHRENBERG, M. C. A linguagem da cultura corporal sob o olhar de professores da educação infantil. Pro-Posições, Campinas, v. 25, n. 1, p. 181-198, dez. 2015. DOI: http://dx.doi.org/10.1590/S0103-73072014000100010. Disponível em: http://www.scielo.br/scielo.php?pid=S010373072014000100010\&script=sci_abstract\&tlng=pt. Acesso em: 19 mar. 2019.

FERREIRA, D. L.; BORTOLETO M. A. C.; SILVA, E. Segurança no circo: questão de prioridade. Várzea Paulista: Fontoura, 2014.

GUZZO, M. S. L. Risco como estética, corpo como espetáculo. São Paulo: Annablume, 2009.

LIPPI, B. G. Formação contínua de professores de Educação Física no estado de São Paulo: Quais as políticas em jogo? 2009. 217 f. Dissertação (Mestrado em Educação) Faculdade de Educação, Universidade de São Paulo, 2009.

LOPES, D. C.; PARMA, M. Construção de malabares passo a passo. 1. ed. Várzea Paulista: Fontoura, 2016.

MIRANDA, R. de C. F. Do tecido à lona: as práticas circenses no tear da formação inicial em educação física. 2015. 165 f. Tese (Doutorado em Educação) - Faculdade de Educação, Universidade Estadual de Campinas, Campinas, 2015.

MIRANDA, R. de C. F.; AYOUB, E. Por entre as brechas dos muros da universidade: o circo como componente curricular na formação inicial em educação física. Revista Portuguesa de Educação, v. 30, n. 2, p. 59-87, 2017. DOI: http://dx.doi.org/10.21814/rpe.8871. Disponível em: http://www.scielo.mec.pt/scielo.php?script=sci_arttext\&pid=S0871-

91872017000200004. Acesso em: 20 fev. 2018.

MIRANDA, R. de C. F.; BORTOLETO, M. A. C. O circo na formação inicial em educação física: um relato autoetnográfico. Revista Brasileira de Ciências do Esporte, v. 40, n. 1, p. 39-45, 2018.

MIRANDA, R. de C. F.; BORTOLETO, M. A. C. Saberes e práticas circenses: analisando os currículos dos cursos de pedagogia das universidades públicas paulistas. Revista Ensaio Geral (UFPA), v. 3, n. 3, p. 79-85, 2014.

NEIRA, M. G. Formação para a docência: o lugar da Educação Física na educação básica. In: SCHNEIDER, O. et al. Educação Física, esporte e sociedade: temas emergentes. São Cristóvão: Editora da UFS, 2008. 
ONTAÑÓN, T. B. Circo na escola: por uma educação corporal, artística e estética. 2016. 214 f. Tese (Doutorado em Educação Física) - Faculdade de Educação Física, Universidade Estadual de Campinas, Campinas, 2016.

ONTAÑÓN, T.; DUPRAT, R. M.; BORTOLETO, M. A. C. Educação física e atividades circenses: "o estado da arte". Revista Movimento, Porto Alegre, v. 18, n. 2, p. 149-168, abr./jun. 2012.

PIMENTA, S. G. Formação de professores: identidade e saberes da docência In: PIMENTA, S. G. (org.). Saberes pedagógicos e atividade docente. 3. ed. São Paulo: Cortez, 2002. p. 1534.

REIS, M. E. T.; AFFONSO, S. B. Os programas de formação continuada e sua relação com os saberes docentes. Revista de Educação do Curso de Pedagogia do Campus Avançado de Jataí da Universidade Federal de Goiás, v. 1, n. 3, jan./jul. 2007.

SILVA, E. Aprendizes permanentes: circenses e a construção da produção do conhecimento no processo histórico. In: BORTOLETO, M. A. C.; ONTAÑÓN, T. B.; SILVA, E. Circo: horizontes educativos. Campinas-SP: Autores Associados, 2016. p. 7-26.

SILVA, M. O. P. A análise de necessidades de formação na formação contínua de professores: um caminho para integração escolar. 2000. 286 f. Tese (Doutorado em Educação) - Faculdade de Educação da Universidade de São Paulo, São Paulo, 2000. Disponível em: http://www.teses.usp.br/teses/disponiveis/48/48134/tde-16102001-100517/ptbr.php. Acesso em: 5 nov. 2018.

TARDIF, M. Saberes docentes e formação profissional. 2. ed. Petrópolis: Vozes, 2002.

TIAEN, M. S. As atividades circenses na formação continuada do professor de Educação Física. 2013. 132 f. Dissertação (Mestrado em Educação) - Faculdade de Educação, Universidade Federal do Mato Grosso do Sul, Corumbá-MS, 2013.

UNESCO. Declaração mundial sobre educação para todos: satisfação das necessidades básicas de aprendizagem. UNESCO: Jomtien, 1990.

WALLON, E. O circo no risco da arte. Trad. Ana Alvarenga, Augustin de Tugny e Cristiane Lage. Belo Horizonte: Autêntica, 2009.

Recebido em: 20/05/2019

Revisado em: 09/04/2020

Aprovado em: 05/02/2021

Publicado em: 15/03/2021 